\title{
Dissociable Contributions of the Human Amygdala and Orbitofrontal Cortex to Incentive Motivation and Goal Selection
}

\author{
F. Sergio Arana, ${ }^{1}$ John A. Parkinson, ${ }^{1}$ Elanor Hinton, ${ }^{2}$ Anthony J. Holland, ${ }^{2}$ Adrian M. Owen, ${ }^{3}$ and Angela C. Roberts ${ }^{1}$ \\ ${ }^{1}$ Department of Anatomy, University of Cambridge, Cambridge CB2 3DY, United Kingdom, ${ }^{2}$ Section of Developmental Psychiatry, Department of \\ Psychiatry, Douglas House, Cambridge CB2 2AH, United Kingdom, ${ }^{3}$ Medical Research Council Cognition and Brain Unit, Cambridge CB2 2EF, United \\ Kingdom, and The Wolfson Brain Imaging Centre, Addenbrooke's Hospital, Cambridge CB2 2QQ, United Kingdom
}

Theories of incentive motivation attempt to capture the way in which objects and events in the world can acquire high motivational value and drive behavior, even in the absence of a clear biological need. In addition, for an individual to select the most appropriate goal, the incentive values of competing desirable objects need to be defined and compared. The present study examined the neural substrates by which appetitive incentive value influences prospective goal selection, using positron emission tomographic neuroimaging in humans. Sated subjects were shown a series of restaurant menus that varied in incentive value, specifically tailored for each individual, and in half the trials, were asked to make a selection from the menu.

The amygdala was activated by high-incentive menus regardless of whether a choice was required. Indeed, activity in this region varied as a function of individual subjective ratings of incentive value. In contrast, distinct regions of the orbitofrontal cortex were recruited both during incentive judgments and goal selection. Activity in the medial orbital cortex showed a greater response to high-incentive menus and when making a choice, with the latter activity also correlating with subjective ratings of difficulty. Lateral orbitofrontal activity was observed selectively when participants had to suppress responses to alternative desirable items to select their most preferred. Taken together, these data highlight the differential contribution of the amygdala and regions within the orbitofrontal cortex in a neural system underlying the selection of goals based on the prospective incentive value of stimuli, over and above homeostatic influences.

Key words: emotion; imaging; pet (positron emission tomography); goal-directed action; appetitive; food preference

\section{Introduction}

Contemporary theories of motivation emphasize the way in which stimuli in the environment attract our attention and act as incentives for our behavior (Bindra, 1974; Dickinson and Balleine, 2002) over and above the homeostatic control of behavior to satisfy basic needs (Hull, 1943). Indeed, television advertisers have tried for many years to increase our desire for commodities we do not necessarily need, and enhanced responsiveness to external stimuli can underlie aberrant behavior such as cueinduced relapse to drug abuse (Childress et al., 1999). When faced with multiple desirable commodities the brain must define and compare their incentive values to determine which ones will guide action (Montague and Berns, 2002). Although both the amygdala and the orbitofrontal cortex have been implicated in

Received June 4, 2003; revised Aug. 29, 2003; accepted Aug. 29, 2003.

This work was supported by the Medical Research Council (including a Career Establishment grant to A.C.R.), a Joseph P. O'Hern Scholarship for Travel and Study in Europe sponsored by the Phi Beta Kappa National Honor Society (F.S.A.), a Grindley Fund award, Cambridge, United Kingdom, and a private bequest to the Prader-Willi Association, United Kingdom (E.H.). This is a publication within the Medical Research Council Centre on Behavioral and Clinical Neuroscience. We thank the radiography team at the Wolfson Brain Imaging Centre, Cambridge, United Kingdom.

Correspondence should be addressed to Dr. John A Parkinson, Department of Anatomy, University of Cambridge, Downing Street, Cambridge CB2 3DY, United Kingdom. E-mail: jp@cartab.net

F. Sergio Arana's present address: Department of Pharmacology and Physiology, University of Rochester School of Medicine and Dentistry, Rochester, NY 14642.

Copyright $\odot 2003$ Society for Neuroscience $\quad$ 0270-6474/03/239632-07\$15.00/0 this process (Tremblay and Schultz, 1999; Baxter et al., 2000; Parkinson et al., 2001; Balleine et al., 2003; Pears et al., 2003; Schoenbaum et al., 2003) there is little experimental evidence differentiating their contribution (Schoenbaum et al., 1998; Bechara et al., 1999; Schoenbaum et al., 2000).

Studying the motivational control of behavior by food, in humans, is a particularly appropriate approach to this issue because it underlies a universal and highly adaptive functional mechanism, and it has already been shown that the amygdala and orbitofrontal cortex are critical for a variety of food-motivated behaviors in animals (for review, see Gallagher, 2001; Cardinal et al., 2002). A specific role for the amygdala in appetitive motivation has also been demonstrated in humans (Hamann et al., 1999; LaBar et al., 2001; Morris and Dolan, 2001; O'Doherty et al., 2002; Anderson et al., 2003), but although neuroimaging experiments have studied intrinsic homeostatic processes (e.g., the influence of changes in hunger state, through satiety, on food value; Tataranni et al., 1999; O'Doherty et al., 2000; Small et al., 2001), little is known about the neural processing of the extrinsic determinants of value (learned through past experience; Dickinson and Balleine, 1994, 2002) that produce desire in the absence of a deficit state (e.g., the offer of chocolate cake after a large meal). Moreover, the neural mechanisms by which incentive value is used to select between multiple competing goals has been studied little. 
To address these issues, positron emission tomography (PET) was used in sated humans to compare neural activity associated with processing the incentive value of different food items, presented in the form of a restaurant menu, with that involved in using the incentive information to guide menu selection. Because food value is highly variable between individuals, subjects were initially given a questionnaire to establish their food preferences. In the subsequent scanning session, subjects were asked to imagine they were in a restaurant and to consider menu items as if they were subsequently going to order and eat those items; with the menu items tailored to each subject's food preferences. It was hypothesized that although amygdala activity would be related to processing incentive value, the orbitofrontal cortex would be particularly involved in using this information in the selection process.

\section{Materials and Methods}

Subjects. Twelve healthy, right-handed, male volunteers with no history of neurological illness and with an average age of $27 \pm 2.16$ years participated in this study. Each subject underwent a structural magnetic resonance imaging (MRI) scan and 12 PET scans within a single session. All subjects gave informed, written consent for participation in the study after its nature and possible consequences had been explained to them. The study was approved by the Local Research and Ethics Committee, Cambridge, United Kingdom.

Image acquisition and data analysis. For each subject, a threedimensional MRI volume $(256 \times 256 \times 128$ pixels, $3 \mathrm{~mm}$ thick $)$ was acquired. Structural MRI scans were used solely for medical diagnostic purposes. PET scans were obtained with the General Electric Advance system (General Electric, Milwaukee, WI), which produces 35 image slices at an intrinsic resolution of $\sim 4.0 \times 5.0 \times 4.5 \mathrm{~mm}$. Using the bolus $\mathrm{H}_{2}{ }^{15} \mathrm{O}$ method, regional cerebral blood flow was measured during three separate scans for each of the four experimental conditions (total $=12$ scans). For each scan, subjects received a $20 \mathrm{sec}$ intravenous bolus of $\mathrm{H}_{2}{ }^{15} \mathrm{O}$ through a forearm cannula at a concentration of $300 \mathrm{Mbq}$ per milliliter and a flow rate of $10 \mathrm{ml}$ per minute. With this method, each scan provides an image of regional cerebral blood flow ( $\mathrm{rCBF}$ ) integrated over a period of $90 \mathrm{sec}$ from when the tracer first enters the cerebral circulation (i.e., each image was acquired over $90 \mathrm{sec}$ ). The scans were preprocessed individually and then combined with the other subjects' scans for collective statistical analysis. Both processes were performed using the Statistical Parametric Mapping 99 (SPM99) package provided by the Wellcome Department of Imaging Neuroscience, London, United Kingdom. For preprocessing, the scans were: (1) realigned using the first scan as a reference; (2) normalized for global cerebral blood flow value and spatially normalized using bilinear interpolation to conform to the standard brain described by Talairach and Tournoux (1988) using the standard MRI template produced by the Montreal Neurological Institute, and (3) spatially smoothed using an isotropic Gaussian kernel at $12 \mathrm{~mm}$.

Blood flow changes between the different conditions were estimated for each voxel according to the general linear model, as implemented by the SPM99 method. A subject-specific analysis of covariance model was fitted to the data at each voxel and globally normalized with grand mean scaling. To reduce scan order and movement artifacts, six movement parameters and a scan time order covariate were calculated relative to the anterior commissure. These parameters were then entered as covariates of no interest into SPM99. The significance of a given rCBF difference was assessed by the application of an intensity threshold to the SPM images (Worsley et al., 1992, 1996). This threshold, based on threedimensional (3D) Gaussian random field theory, predicts the likelihood of obtaining a false positive result in an extended 3D field. The current experiment was designed to study the effects on the amygdala and orbitofrontal cortex. Specifically, a priori predictions were made about $\mathrm{rCBF}$ changes occurring in these regions during manipulations of incentive value and choice. Accordingly, regions of interest (ROIs) were created using the Montreal Neurological Institute average brain template and the software package MRIcro version 1.35 (Rorden and Brett, 2000); volume corrections were run within SPM99. The calculated volume of the amygdala ROI was $4435 \mathrm{~mm}^{3}$, whereas that of the entire orbitofrontal cortex was found to be $21,486 \mathrm{~mm}^{3}$. Accordingly, the intensity threshold ( $p<$ 0.05 , corrected) for significance was set to $t=3.28$ and $t=3.6$ for activations occurring within the amygdala or within an area comprising the entire orbitofrontal cortex, respectively. In a parallel study (Hinton, Parkinson, Holland, Arana, Roberts, and Owen, unpublished observations), significant activation was observed in a region of the left medial orbitofrontal cortex $(x=-8, y=42, z=-16)$ during an equivalent comparison (main effect of incentive), using an identical task. On the basis of these independent results, a third ROI was constructed by drawing a $1 \mathrm{~cm}$ radius sphere centered unilaterally around this location. The corresponding threshold for significance within this region $(p<0.05$, corrected) was $t=2.95$ for the main effect of incentive only. For the rest of the brain, an exploratory search involving all peaks within the gray matter (volume, $600 \mathrm{~cm}^{3}$ ) was conducted and the threshold for reporting a peak as significant was set at $p<0.05$, corrected for multiple comparisons.

Experimental design. Subjects were asked to refrain from eating after 10 P.M. the night before testing. Subjects arrived on the test date at $\sim 9$ A.M. and were provided with cheese sandwiches (a common snack in the United Kingdom) and water. Importantly, subjects were asked to eat to the point of satiety, which was described to fall between the feeling of no longer being hungry to that of being overly full. They were asked to keep in mind that they would not be able to eat for $4 \mathrm{hr}$ and to judge the amount of food they consumed accordingly. All subjects had 12 PET scans taken at $8 \mathrm{~min}$ intervals. An instructional screen was presented to subjects (see description of psychological task below) indicating the type of trial, 2 min $15 \mathrm{sec}$ before the beginning of each task. Each subject was scanned in the presence of low background noise and dimmed ambient lighting. The task displays were presented on a touch-sensitive screen controlled by a personal computer with a Pentium microprocessor. The screen was mounted at a viewing distance at which the subject could touch all areas of the screen with the index finger of his right hand. During each scan, the subjects began each task 15 sec before PET acquisition. Scans in which outside disturbance might have affected subjects' attentiveness to the task or movement artifact was too great were not used in the analysis. A total of four scans were discarded for such reasons, each scan belonging to a different subject.

Psychological task. All subjects participated in the "restaurant task," a program created specifically for this study using Visual Basic 6.0 (Microsoft, Reading, UK). In essence, subjects imagined that they were going to a restaurant for an evening meal. They were required to read each menu item, which was created using specific knowledge of the individual's food preferences, and were asked to imagine what it would be like to be presented with it in a restaurant. These items differed in their incentive value, set according to each subject's responses to a food preference questionnaire given approximately 1 week before scanning. This questionnaire established the general food preferences of each subject. From this information, specific menu items were created tailored to an individual's preferences. Furthermore, half the trials required the subjects not only to read the food items and consider their palatability, but also to choose which one they would have. Thus, the task was block designed varying across the two conditions: incentive value of the menu items and choice. Incentive value was classified either to be high or low. Highincentive items were created using the subject's most preferred foods. Low-incentive items were created using foods that subjects were happy to eat but were not their most preferred. Food items that subjects did not like were explicitly avoided. Menu items were matched across incentive conditions for syntax and sentence length. Examples of a high- and lowincentive menu item particular to one subject's preferences were as follows: High: "Aromatic Crispy Duck: Duck, marinated in oriental spices, deep fried until golden and crispy, served with a Hoi Sin sauce, Chinese pancakes, spring onions, and cucumber." Low: "Seared Spiced Plaice Steak: Plaice steak, lightly spiced, and served with a black bean salsa on top of wild rice with sautéed young spinach and sliced button mushrooms."

All subjects performed a practice session with the restaurant task before PET scanning. Of the 12 experimental scans 6 consisted of high- 
incentive menus and 6 of low-incentive menus. Within each of these six, three involved a choice and three did not. The presentation of conditions was counterbalanced across subjects. A maximum of three menu option screens were available per PET scan. Consecutive menu screens were activated after the selection of a menu item. Course designation was counterbalanced across PET scans and across subjects. Choice trials consisted of three items from the same course (e.g., starter, main course, or dessert), which changed across menu screens in a counterbalanced manner. During no-choice trials, food items were presented as full threecourse menus to discourage covert comparison between potentially competing items of the same course. They then activated the next new full three-course menu screen by selecting the last menu item on the screen. This method was used to match for motor responses in the choice condition.

Debriefing and behavioral assessment. After scanning, subjects completed a survey consisting of every menu screen presented during the scanning session. They were asked to rank the incentive value of each menu item from 1 to 5 , with 1 reflecting absolute indifference (i.e., an item not likely to be chosen in a restaurant) and 5 representing a high incentive value (i.e., an item the subject truly liked and would be inclined to select in a restaurant). No menu items were found to be displeasing or to cause any repulsive reaction or feeling of disgust to any subject. Also, subjects were asked to rank the difficulty of making a selection in the choice trials from 1 (difficult) to 5 (easy). Response-time measurements were recorded indicating the length of time spent on each menu screen. The number of screens reached during actual scan acquisition was also noted.

Behavioral statistical analyses. Nonparametric behavioral data obtained from rankings (i.e., incentive and difficulty ratings) were analyzed using the Wilcoxon signed rank test. The Wilcoxon test was used because the ranking data obtained were in a discontinuous format. Parametric data such as reaction time (i.e., the time duration from menu screen onset to the onset of the next trial) and the number of screens reached during the different conditions were analyzed using ANOVA.

\section{Results}

\section{Behavioral measures}

After scanning, subjects rated the incentive value of all menu items that were presented. These ratings validated the experimental design in that the menu items that were created, based on individual subject preferences, were indeed judged by those subjects as being of the appropriate incentive value. Overall, subjects rated the incentive value of menu items in the high-incentivechoice (HC) condition to be significantly higher than that of the low-incentive-choice (LC) condition (Wilcoxon test, $z=3.06$, $p<0.005)$. Similarly, they rated menu items of the high-incentive no-choice (HNC) condition to be of a higher incentive value than that of the low-incentive no-choice (LNC) condition (Wilcoxon test, $z=3.06, p<0.005$ ) (Fig. $1 A$ ). Subjects also rated the difficulty of selecting items during choice trials. Although an attempt was made to match the high- and low-incentive menus for difficulty of choice, it was found that subjects tended to rate selections from high-incentive menus as being more difficult than those for low-incentive menus (Wilcoxon test, $z=2.47, p<0.05$ ) (Fig. $1 B)$. In line with this, it has been demonstrated previously that people will avoid having to make a decision between two highly valued choices if a third, less difficult, option is available (Tversky and Shafir, 1992). Response time per menu screen was analyzed across conditions with a repeated-measures ANOVA. There were no significant differences observed across the varying conditions $\left(F_{(3,33)}=0.83, p=0.46\right)$, with the average times in seconds $( \pm$ $\mathrm{SE})$ to complete a menu 53.2 $\pm 5.8,47.9 \pm 5.3,50.4 \pm 3.7,50.6 \pm$ 5.6 in HC, LC, HNC, and LNC conditions, respectively. Finally, no significant difference in the number of menu screens reached within each PET scan was found between any of the conditions
A. Incentive value B. Difficulty of
choice
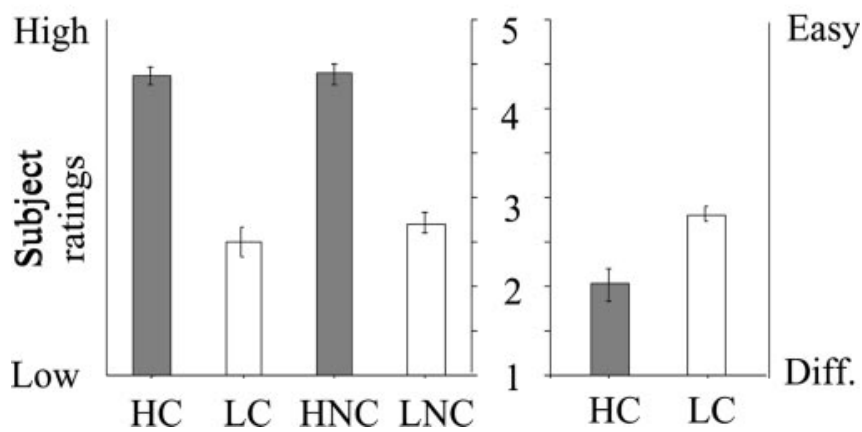

Figure 1. Subject-rated behavioral measures. A, Average subject ratings (with SEM bars) of incentive value of menu items in each experimental condition. The rating scale ranged from 1 to 5 , with higher scores indicating greater incentive value for menu items. High-incentive conditions were rated as being of a significantly greater incentive value than low-incentive conditions (for both choice and nonchoice comparisons: Wilcoxon $z=3.06, p<0.005$ ). B, Average subject ratings of the difficulty of making choices relating to menu items in the high- and low-incentive categories. The rating scale ranged from 1 to 5 , with lower scores indicating a greater difficulty (Diff.) in selecting a goal. Subjects found it significantly more difficult to make choices regarding high-incentive menu items than low-incentive items (Wilcoxon $z=2.47$, $p<0.05)$.

$(p>0.05)$, the averages ( $\pm \mathrm{SE}$ ), given in the same order as above, were $2.5 \pm 0.16,2.5 \pm 0.16,2.47 \pm 0.11$, and $2.53 \pm 0.16$.

\section{Incentive representations in amygdala and orbitofrontal cortex}

Because the two conditions manipulated in this study were food incentive value and choice, PET was used to compare differences between high- and low-incentive condition states during choice and no-choice trials. Comparisons considered for main effect of incentive value revealed a significant increase in $\mathrm{rCBF}$ for the high-incentive condition compared with the low-incentive condition in the left amygdala $(x=-16, y=-4, z=-14 ; t=3.31$, $p<0.05$, corrected) (Fig. $2 A$ ). This comparison also revealed a significant peak of activity in a region of the left medial orbitofrontal cortex $(x=-8, y=42, z=-20, t=3.3, p<0.05$, corrected) (Fig. $2 B$ ), which was at almost identical coordinates $(x=-8, y=44, z=-20)$ to an rCBF change observed in a parallel study using a formally identical comparison between conditions (Hinton, Parkinson, Holland, Arana, Roberts and Owen, unpublished observations). Thus, both the amygdala and the orbitofrontal cortex showed increased activity when subjects were considering menus of high incentive value compared with those of low incentive value.

\section{Goal selection subserved by the orbitofrontal cortex}

Two regions in the orbitofrontal cortex were associated with different aspects of choice. For the contrast comparing the choice with the no-choice condition, activity was observed in the left medial orbitofrontal cortex $(x=-8, y=36, z=-16$; $t=3.75$, $p<0.05$, corrected) (Fig. $3 A$ ) in a region similar to that showing significant activity for the main effect of incentive (Fig. 2 B). Furthermore, for the interaction of incentive value on choice, a significant activation specifically associated with selecting from high-incentive menu items was demonstrated in the right lateral orbitofrontal cortex $(x=48, y=52, z=-14 ; t=3.62, p<0.05$, corrected) (Fig. $3 B$ ). In the post hoc whole-brain corrected analysis, the right striatum $(x=16, y=14, z=4 ; t=5.09, p<0.05)$ 


\section{High - Low Incentive}
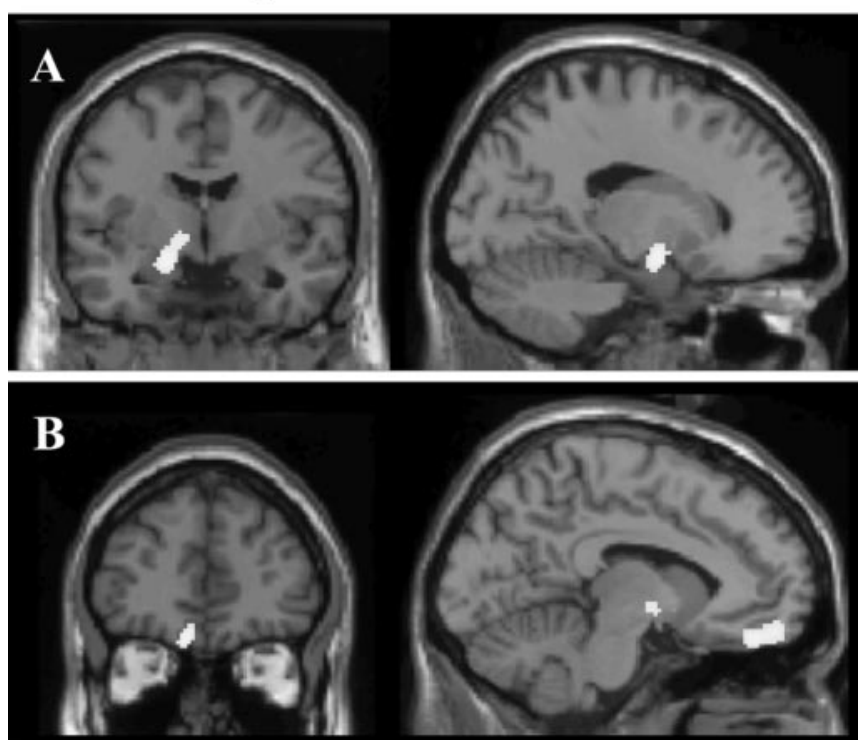

Figure 2. Significant $r(B F$ changes in the main effect contrast of incentive value. $A$, A region of the left amygdala $(x=-16, y=-4, z=-14)$ showed increased $\mathrm{rCBF}$ in the highincentive condition. A similar region of the left amygdala $(x=-16, y=-6, z=-18)$ showed a significant covariation of activity with subject-rated incentive value of the menu items (see Fig. 4A). B, A region of the left medial orbitofrontal cortex $(x=-8, y=44, z=$ $-20)$ also showed increased rCBF in the high-incentive condition.

(Fig. 3C) was the only region showing significant activation for the main effect of choice.

\section{Incentive value correlates with amygdala $\mathrm{rCBF}$}

Significant changes in rCBF for the main effect contrast of incentive value was based on the experimenters' classification of menu items into high- and low-incentive categories as predicted by subjects' responses on a food preference questionnaire. However, to establish whether changes in $\mathrm{rCBF}$ were driven specifically by the incentive value of menu items as rated by individuals themselves on the day of the study, a covariate analysis of brain activity was performed incorporating the subjects' incentive ratings. A significant correlation of $\mathrm{rCBF}$ activity with incentive value was observed in the left amygdala $(x=-16, y=-6, z=-18$; $t=$ $3.35 ; p<0.05$ ) (Fig. $4 A$ ), demonstrating that increases in rCBF in the amygdala were associated with increases in the incentive value of prospective foods. No other areas of the brain showed a significant covariation of $\mathrm{rCBF}$ with incentive ratings.

\section{Selection difficulty correlates with medial orbital rCBF}

Given the apparent involvement of two distinct regions of the orbitofrontal cortex in selecting goals, it was determined whether regional changes in $\mathrm{rCBF}$ were specifically correlated with the goal-selection processes. rCBF in the left medial orbitofrontal cortex was found to correlate significantly with the difficulty of the choice $(x=-14, y=42, z=-24 ; t=4.25, p<0.05)$ (Fig. $4 B)$. The coordinates of this region were similar to those of the peaks observed for both the main effect of choice $(x=-8, y=36$, $z=-16)$ and of incentive $(x=-8, y=44, z=-20)$. Given the proximity of these activation peaks, it is hypothesized that this area integrates mnemonic information regarding the food items being imagined, including their value, to guide choice. However, it is important to note that because of the relatively low resolution of PET, and the implementation of $12 \mathrm{~mm}$ smoothing in the

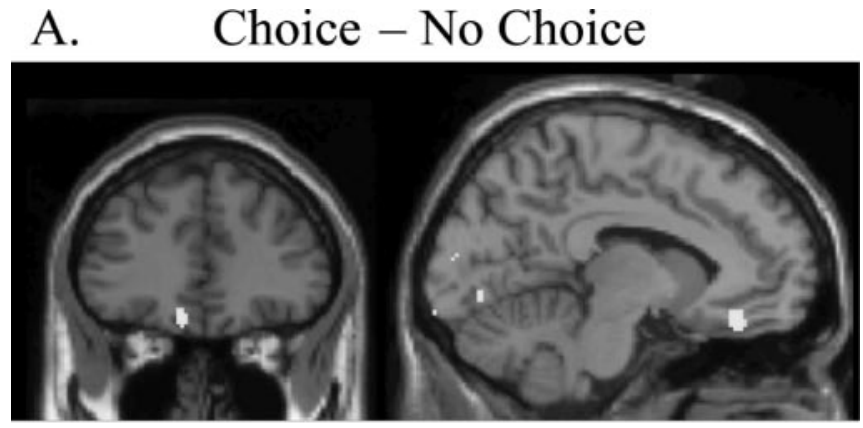

\section{B. Choice $x$ High Incentive}

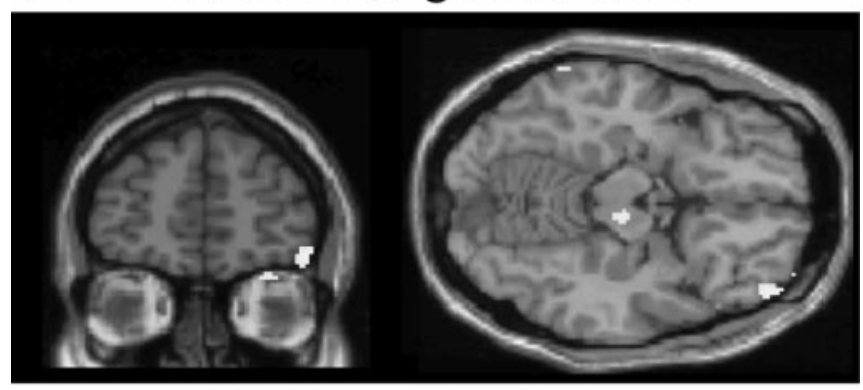

C.

Choice - No Choice

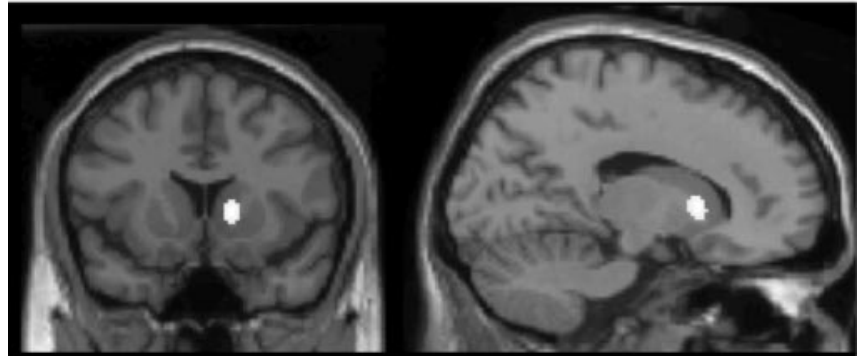

Figure 3. Significant $\mathrm{rCBF}$ changes in the main effect contrast of choice $(A$ and $C$ ) and in the interaction between incentive value and choice $(B) . A$, An area of left medial orbitofrontal cortex $(x=-8, y=36, z=16)$ showed significantly greater rCBF in choice trials over no-choice trials. This peak is in a location similar to the one observed for the main effect contrast of incentive value (Fig. 2B). B, A region of the right lateral orbitofrontal cortex $(x=48, y=52$, $z=-14$ ) showed increased activity for the incentive value $X$ choice interaction, specifically when subjects selected between high-incentive alternatives. $C$, Significant changes in $\mathrm{rCBF}$ were also seen in the medial striatum $(x=16, y=14, z=4)$ in the main effect contrast of choice.

present study, it is not conclusive that these activation peaks relate to the same population of neurons.

\section{Discussion}

The present study, using PET neuroimaging in humans, demonstrates the power of imagination and mnemonic retrieval in generating a representation of value that, in the natural world, very often underlies human motivation and goal-directed behavior in the absence of tangible or immediate primary rewards. Three major findings emerge: first, both the amygdala and the medial orbitofrontal cortex are activated when individuals consider the appetitive incentive value of foods. Indeed, $\mathrm{rCBF}$ in the amygdala covaried specifically with subjects' ratings of incentive value. Because the specific value of individual foods is determined predominantly through past experience, the results demonstrate a role for these two regions in processing the learned value of motivationally relevant stimuli. Second, the medial orbitofrontal cortex is also involved when incentive value informs goal selection, not only showing differential activity in the choice contrast 
but also showing varying activity according to the difficulty of the choice being made. Finally, the selection process also activated the right lateral orbitofrontal cortex, specifically though, when subjects chose from high-incentive menus. Taken together, these data highlight the differential contribution of the amygdala and distinct regions within the orbitofrontal cortex in the processes of incentive motivation and goal selection.

\section{Neural systems underlying contributions to incentive value} In the present study, orbitofrontal and amygdala activation was observed in the absence of actual foods, which is consistent with the involvement of these structures in the preparatory component of behavior (Everitt, 1990; Burns et al., 1993). Furthermore, subjects were tested in a sated state; thus, the increased activations to high-incentive menu items in both these regions were a reflection primarily of the processing of specific food value over and above that provided by homeostatic mechanisms mediating hunger. Along with findings from a previous study (LaBar et al., 2001) in which amygdala activity reflected differences in the incentive value of food pictures induced by changes in hunger state, these data support the hypothesis that the amygdala acts as a point of convergence for value information influenced by homeostasis as well as past experience of the hedonic properties of the food (present study). In the present study, no changes in activity were observed in the insular cortex or hypothalamus (i.e., $p=1$ ); both structures are sensitive to the modulatory effects of hunger on feeding (Tataranni et al., 1999; Small et al., 2001) and the processing of food-related stimuli (Morris and Dolan, 2001). Indeed, in an associated paper (Hinton, Parkinson, Holland, Arana, Roberts and Owen, unpublished observations) subjects were presented with an equivalent version of the restaurant task, in both the sated and hungry state (on separate occasions), and increased activity was seen in the insula and hypothalamus during the hungry state, suggesting some neural specificity in different components of motivational influence.

It has also been shown that hunger can modulate incentiverelated activity in the orbitofrontal cortex. Although no incentive-related changes in orbitofrontal activity were observed in the study of LaBar et al. (2001) (possibly because of technical limitations of their functional MRI procedure, as the authors suggest), Morris and Dolan (2001) have reported positive correlations between individual ratings of hunger state and activity in posterior orbitofrontal cortex elicited by food pictures. However, the focus of activity in this latter study was far more posterior $(\sim 3$ $\mathrm{cm})$ and lateral $(\sim 2.5 \mathrm{~cm})$ to that observed in the present study and far closer to a region in which the level of activity has been shown to decline to an odor of a food as a consequence of sensory specific satiety (O’Doherty et al., 2000).

Whether the incentive-related activity to menu items in both the medial orbitofrontal cortex and amygdala represent different types of value information remains to be determined. Certainly, in the present study the activity within the amygdala and medial orbitofrontal cortex did not correlate with one another $(r=$ $-0.04)$. Moreover, although rCBF in the amygdala correlated with the specific magnitude of the incentive value of individual
B. Medial orbitofrontal $\mathrm{rCBF}$ and choice difficulty

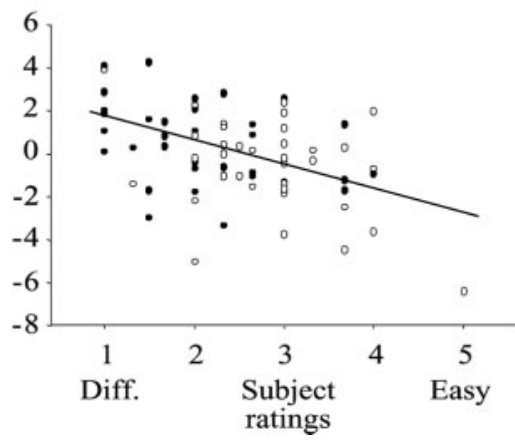


low-incentive foods; thus, when choosing between these foods subjects may have had to suppress responses to the other desirable items to select their most preferred item. Such a function of the lateral orbitofrontal cortex in response suppression has been suggested previously (Elliott et al., 2000a) and is consistent with findings from several other neuroimaging experiments (Elliott and Dolan, 1999; Elliott et al., 2000b; O’Doherty et al., 2001; Small et al., 2001). Indeed the dual medial and lateral orbitofrontal activations in the present study are consistent with the double dissociation of effects of medial and lateral lesions of the orbitofrontal cortex on a visual discrimination learning task in rhesus monkeys demonstrated by Iversen and Mishkin (1970). Medial orbitofrontal lesions produced impairments in associating stimuli with reward value, whereas lateral orbitofrontal lesions resulted in a failure to inhibit responding to the previously rewarded stimulus.

Finally, a significant increase in $\mathrm{rCBF}$ was also observed in the medial striatum in the choice contrast. Although the basal ganglia are implicated in certain aspects of food palatability, notably disgust responses (Calder et al., 2001), and also in reward processing (Schultz et al., 1993; Knutson et al., 2001), the most likely explanation for striatal activity specifically in the choice contrast, rather than the incentive contrast, relates to the proposed role for corticostriatal circuits in strategy and response selection (Alexander et al., 1986; Redgrave et al., 1999; Montague and Berns, 2002).

\section{Summary and Conclusions}

The amygdala and the orbitofrontal cortex play a critical role in appraising the appetitive value of stimuli, to guide online goal selection based on relative reward value (Davidson and Irwin, 1999; Montague and Berns, 2002). Specifically, amygdala activity correlates with an individuals subjective rating of intensity of both extrinsically determined (present study) as well as homeostatically controlled incentive value (Morris and Dolan, 2001), with the arousing content of emotional stimuli and its subsequent mnemonic impact (Canli et al., 2000) and with the intensity of pleasant and unpleasant olfactory stimulation (Anderson et al., 2003). Thus, the amygdala may be fundamental in providing the magnitude signal for value judgments based on prospective, or conditioned, cues. Such emotional cues can engage multiple psychological processes, including attention and associability, the effectiveness of memory consolidation, pavlovian arousal, and goal-directed action (Dickinson and Balleine, 1994; Cahill and McGaugh, 1996; Holland, 1997; Killcross et al., 1997; Holland and Gallagher, 1999; Parkinson et al., 2000; Anderson and Phelps, 2001). As such, the present study supports the hypothesis that the medial and lateral orbitofrontal cortices underlie the process by which the prospective values of complex food stimuli are represented and compared to select an appropriate goal to direct action. Indeed, the orbitofrontal cortex as a whole may act more generally to integrate diverse aspects of goal information, including value, sensory, experiential and semantic components to guide prospective behavior.

\section{References}

Alexander GE, Delong MR, Strick PL (1986) Parallel organization of functionally segregated circuits linking basal ganglia and cortex. Annu Rev Neurosci 9:357-381.

Anderson AK, Phelps EA (2001) Lesions of the human amygdala impair enhanced perception of emotionally salient events. Nature 411:305-309.

Anderson AK, Christoff K, Stappen I, Panitz D, Ghahremani DG, Glover G, Gabrieli JD, Sobel N (2003) Dissociated neural representations of intensity and valence in human olfaction. Nat Neurosci 6:196-202.
Balleine BW, Killcross AS, Dickinson A (2003) The effect of lesions of the basolateral amygdala on instrumental conditioning. J Neurosci 23:666-675.

Baxter MG, Parker A, Lindner CC, Izquierdo AD, Murray EA (2000) Control of response selection by reinforcer value requires interaction of amygdala and orbital prefrontal cortex. J Neurosci 20:4311-4319.

Bechara A, Damasio H, Damasio AR, Lee GP (1999) Different contributions of the human amygdala and ventromedial prefrontal cortex to decisionmaking. J Neurosci 19:5473-5481.

Bindra D (1974) A motivational view of learning, performance and behavioral modification. Psychol Rev 81:199-213.

Burns LH, Robbins TW, Everitt BJ (1993) Differential effects of excitotoxic lesions of the basolateral amygdala, ventral subiculum and medial prefrontal cortex on responding with conditioned reinforcement and locomotor activity potentiated by intra-accumbens infusions of D-amphetamine. Behav Brain Res 55:167-183.

Cahill L, McGaugh JL (1996) Modulation of memory storage. Curr Opin Neurobiol 6:237-242.

Calder AJ, Lawrence AD, Young AW (2001) Neuropsychology of fear and loathing. Nat Rev Neurosci 2:352-363.

Canli T, Zhao Z, Brewer J, Gabrieli JD, Cahill L (2000) Event-related activation in the human amygdala associates with later memory for individual emotional experience. J Neurosci 20:RC99.

Cardinal RN, Parkinson JA, Hall J, Everitt BJ (2002) Emotion and motivation: the role of the amygdala, ventral striatum, and prefrontal cortex. Neurosci Biobehav Rev 26:321-352.

Childress AR, Mozley PD, McElgin W, Fitzgerald J, Reivich M, O'Brien CP (1999) Limbic activation during cue-induced cocaine craving. Am J Psychiatry 156:11-18.

Davidson RJ, Irwin W (1999) The functional neuroanatomy of emotion and affective style. Trends Cogn Sci 3:11-21.

Dickinson A, Balleine B (1994) Motivational control of goal-directed action. Animal Learn Behav 22:1-18.

Dickinson A, Balleine B (2002) The role of learning in the operation of motivational systems. In: Steven's handbook of experimental psychology, Ed 3 (Pashler H, Gallistel R, eds), pp 497-533. New York: Wiley.

Elliott R, Dolan RJ (1999) Differential neural responses during performance of matching and nonmatching to sample tasks at two delay intervals. J Neurosci 19:5066-5073.

Elliott R, Dolan RJ, Frith CD (2000a) Dissociable functions in the medial and lateral orbitofrontal cortex: evidence from human neuroimaging studies. Cereb Cortex 10:308-317.

Elliott R, Friston KJ, Dolan RJ (2000b) Dissociable neural responses in human reward systems. J Neurosci 20:6159-6165.

Everitt BJ (1990) Sexual motivation - a neural and behavioral analysis of the mechanisms underlying appetitive and copulatory responses of male rats. Neurosci Biobehav Rev 14:217-232.

Gallagher M (2001) The amygdala and associative learning. In: The Amygdala: a Functional Analysis, Ed 2 (Aggleton JP, ed), pp 311-330. Oxford: OUP.

Hamann SB, Ely TD, Grafton ST, Kilts CD (1999) Amygdala activity related to enhanced memory for pleasant and aversive stimuli. Nat Neurosci 2:289-293.

Holland PC (1997) Brain mechanisms for changes in processing of conditioned stimuli in Pavlovian conditioning: Implications for behavior theory. Animal Learn Behav 25:373-399.

Holland PC, Gallagher M (1999) Amygdala circuitry in attentional and representational processes. Trends Cogn Sci 3:65-73.

Hull CL (1943) Principles of Behav, an Introduction to Behav Theory. Oxford: Appleton-Century.

Iversen SD, Mishkin M (1970) Perseverative interference in monkeys following selective lesions of the inferior prefrontal convexity. Exp Brain Res 11:376-386.

Killcross S, Robbins TW, Everitt BJ (1997) Different types of fearconditioned behaviour mediated by separate nuclei within amygdala. $\mathrm{Na}-$ ture 388:377-380.

Knutson B, Adams CM, Fong GW, Hommer D (2001) Anticipation of increasing monetary reward selectively recruits nucleus accumbens. J Neurosci 21:RC159.

LaBar KS, Gitelman DR, Parrish TB, Kim YH, Nobre AC, Mesulam MM (2001) Hunger selectively modulates corticolimbic activation to food stimuli in humans. Behav Neurosci 115:493-500. 
Montague PR, Berns GS (2002) Neural economics and the biological substrates of valuation. Neuron 36:265-284.

Morris JS, Dolan RJ (2001) Involvement of human amygdala and orbitofrontal cortex in hunger- enhanced memory for food stimuli. J Neurosci 21:5304-5310.

O’Doherty J, Rolls ET, Francis S, Bowtell R, McGlone F, Kobal G, Renner B, Ahne G (2000) Sensory-specific satiety-related olfactory activation of the human orbitofrontal cortex. NeuroReport 11:893-897.

O’Doherty J, Kringelbach ML, Rolls ET, Hornak J, Andrews C (2001) Abstract reward and punishment representations in the human orbitofrontal cortex. Nat Neurosci 4:95-102.

O’Doherty JP, Deichmann R, Critchley HD, Dolan RJ (2002) Neural responses during anticipation of a primary taste reward. Neuron 33:815-826.

Parkinson JA, Robbins TW, Everitt BJ (2000) Dissociable roles of the central and basolateral amygdala in appetitive emotional learning. Eur J Neurosci 12:405-413.

Parkinson JA, Crofts HS, McGuigan M, Tomic DL, Everitt BJ, Roberts AC (2001) The role of the primate amygdala in conditioned reinforcement. J Neurosci 21:7770-7780.

Pears A, Parkinson JA, Hopewell L, Everitt BJ, Roberts AC (2003) Lesions of the orbitofrontal, but not medial prefrontal cortex, disrupt conditioned reinforcement in primates. J Neurosci, in press.

Redgrave P, Prescott TJ, Gurney K (1999) The basal ganglia: a vertebrate solution to the selection problem? Neuroscience 89:1009-1023.

Rorden C, Brett M (2000) Stereotaxic display of brain lesions. Behav Neurol 12:191-200.

Schoenbaum G, Chiba AA, Gallagher M (1998) Orbitofrontal cortex and basolateral amygdala encode expected outcomes during learning. Nat Neurosci 1:155-159.
Schoenbaum G, Chiba AA, Gallagher M (2000) Changes in functional connectivity in orbitofrontal cortex and basolateral amygdala during learning and reversal training. J Neurosci 20:5179-5189.

Schoenbaum G, Setlow B, Nugent SL, Saddoris MP, Gallagher M (2003) Lesions of orbitofrontal cortex and basolateral amygdala complex disrupt acquisition of odor-guided discriminations and reversals. Learn Mem 10:129-140.

Schultz W, Apicella P, Ljungberg T, Romo R, Scarnati E (1993) RewardRelated Activity in the Monkey Striatum and Substantia-Nigra. Prog Brain Res 99:227-235.

Small DM, Zatorre RJ, Dagher A, Evans AC, Jones-Gotman M (2001) Changes in brain activity related to eating chocolate: from pleasure to aversion. Brain 124:1720-1733.

Talairach J, Tournoux P (1988) Co-planar stereotaxic atlas of the human brain. New York: Thieme Medical.

Tataranni PA, Gautier JF, Chen K, Uecker A, Bandy D, Salbe AD, Pratley RE, Lawson M, Reiman EM, Ravussin E (1999) Neuroanatomical correlates of hunger and satiation in humans using positron emission tomography. Proc Natl Acad Sci USA 96:4569-4574.

Tremblay L, Schultz W (1999) Relative reward preference in primate orbitofrontal cortex. Nature 398:704-708.

Tversky A, Shafir E (1992) Choice under conflict: the dynamics of deferred decision. Psychol Sci 3:358-361.

Worsley KJ, Evans AC, Marrett S, Neelin P (1992) A three-dimensional statistical analysis for CBF activation studies in human brain. J Cereb Blood Flow Metab 12:900-918.

Worsley KJ, Marrett P, Neelin AC, Friston KJ, Evans AC (1996) A unified statistical approach for determining significant signals in images of cerebral activation. Hum Brain Map 4:58-73. 